Illinois State University

ISU ReD: Research and eData

Theses and Dissertations

3-23-2017

\title{
The Effects of TRX Suspension Training on an Asymmetrical Weight Shift During a Double-Leg Squat
}

Samantha J. Shruck

Illinois State University, sjshruc@ilstu.edu

Follow this and additional works at: https://ir.library.illinoisstate.edu/etd

Part of the Biomechanics Commons

\section{Recommended Citation}

Shruck, Samantha J., "The Effects of TRX Suspension Training on an Asymmetrical Weight Shift During a Double-Leg Squat" (2017). Theses and Dissertations. 711.

https://ir.library.illinoisstate.edu/etd/711

This Thesis is brought to you for free and open access by ISU ReD: Research and eData. It has been accepted for inclusion in Theses and Dissertations by an authorized administrator of ISU ReD: Research and eData. For more information, please contact ISUReD@ilstu.edu. 


\title{
THE EFFECTS OF TRX SUSPENSION TRAINING ON AN ASYMMETRICAL WEIGHT SHIFT DURING A DOUBLE-LEG SQUAT
}

\author{
Samantha J. Shruck
}

\section{Pages}

Context: It is estimated that $54 \%$ of all sport related injuries are to the lower extremity, specifically the knee and ankle. Following injury, many individuals demonstrate an asymmetrical weight shift during a double-leg squat, which may increase risk of further injury. Asymmetries are driven by a variety of factors including range of motion and neuromuscular control. The goal of rehabilitation is to identify asymmetrical movement and utilize evidence-based techniques to retrain deficient movement patterns. The double-leg squat is a reliable movement task to identify asymmetrical weight shifts. Based on the theory and purpose of suspension training (TRX), it may be one clinical tool to aid in retraining movement and diminish asymmetrical loading. However, the effects are currently unknown.

Objective: To compare hip kinematics using a tablet-based motion analysis system in individuals with an asymmetrical weight shift during the double-leg squat with and without suspension training. A secondary objective is to describe passive hip rotation range of motion (ROM) in the same individuals.

Design: Cross-Sectional Design.

Patients or other participants: 36 participants screened and 24 identified with an asymmetrical weight shift. 
Main Outcome Measure(s): Bilateral limbs of each participant were assigned as the limb shifted away from (AWAY) and the limb shifted toward (TWD) based on their asymmetrical squat during participant screening. Passive hip internal rotation ROM and external rotation ROM were compared between limbs (AWAY, TWD) utilizing a paired samples $t$ test. Side-to-side differences in hip adduction angle, calculated as the AWAY limb minus the TWD limb, during the double leg squat were compared between conditions (BASE, TRX) using a paired samples $t$ test. Results: No significant difference was observed between the passive hip IR and ER ROM measures between limbs. There was a significant difference between the BASE and TRX double-leg squat conditions on measures of Hip ADD angle difference $(\mathrm{t}(23)=3.11, \mathrm{p}=0.005, \mathrm{~d}=$ 0.63).. The difference score decreased during the TRX condition, indicating a reduction in the asymmetry between limbs.

Conclusions: With no extra coaching provided, the TRX suspension trainer squat task decreased the hip ADD angle difference compared to the BASE squat. Additional research needs to be completed to determine if these effects and be further magnified, but the TRX suspension trainer should be encouraged to be used in the clinical setting as a method for reducing an asymmetrical weight shift during a squat task.

KEYWORDS: Asymmetrical Weight Shift, Squat, TRX Suspension Trainer 


\section{THE EFFECTS OF TRX SUSPENSION TRAINING ON AN ASYMMETRICAL WEIGHT SHIFT DURING A DOUBLE-LEG SQUAT}

SAMANTHA J. SHRUCK

A Thesis Submitted in Partial Fulfillment of the Requirements for the Degree of MASTER OF SCIENCE

School of Kinesiology and Recreation

ILLINOIS STATE UNIVERSITY 
Copyright 2017 Samantha J. Shruck 
THE EFFECTS OF TRX SUSPENSION TRAINING ON AN ASYMMETRICAL WEIGHT

SHIFT DURING A DOUBLE-LEG SQUAT

SAMANTHA J. SHRUCK

COMMITTEE MEMBERS:

Rebecca L. Begalle, Chair

Justin M. Stanek 


\section{ACKNOWLEDGMENTS}

I would like to extend a huge thank you to my thesis committee of Dr. Rebecca Begalle and Dr. Justin Stanek, because without both of you, my thesis would not be what it is. The expertize you both have helped to take my broad topic ideas and create the thesis I now have, and your support has helped to show me that I could complete this. Additionally, I would like to thank the Illinois State University S.M.A.R.T. clinic and Illinois Wesleyan Athletics Department for the use of their facilities.

Thank you to my family who have always been supportive through my years of schooling and always push me to be better. Another thank you to the countless number of friends, coworkers and athletes who acted as sounding boards at whatever time I needed them. Whether athletic trainers or not, all of your input and support helped this thesis become what it has.

And a final thank you to the participants who volunteered to be involved in my study. Without your participation, my thesis would have been nothing more than the first three, unfinished chapters. Thank you again everyone!

S. J. S. 


\section{CONTENTS}

\section{Page}

ACKNOWLEDGMENTS

CONTENTS

ii

TABLES

V

FIGURES

vi

CHAPTER I: INTRODUCTION 1

$\begin{array}{ll}\text { Background } & 1\end{array}$

$\begin{array}{ll}\text { Independent Variables } & 4\end{array}$

Dependent Variables $\quad 4$

$\begin{array}{ll}\text { Research Questions and Hypotheses } & 4\end{array}$

CHAPTER II: REVIEW OF RELATED LITERATURE 6

$\begin{array}{ll}\text { Epidemiology } & 6\end{array}$

$\begin{array}{ll}\text { Relevant Anatomy } & 6\end{array}$

$\begin{array}{ll}\text { Ankle } & 6\end{array}$

$\begin{array}{ll}\text { Knee } & 7\end{array}$

Lumbo-Pelvic-Hip Complex $\quad 8$

Importance of Internal and External Hip Rotation $\quad 9$

The Effect of Lower Extremity Injury on Asymmetrical Movement 10

$\begin{array}{ll}\text { Anterior Cruciate Ligament (ACL) Sprains } & 10\end{array}$

Effects of Injury on Lower Extremity Biomechanics $\quad 10$

$\begin{array}{ll}\text { Asymmetrical Weight Shift } & 12\end{array}$

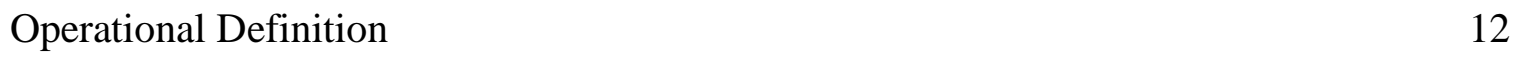


Double-Leg Squats Kinematics

Suspension Training

Background

Lack of Research for Rehabilitation

Conclusion

CHAPTER III: METHODS

Design

Participants

Instrumentation

Procedures

Participant Screening and Baseline Squat

Passive Range of Motion (PROM)

TRX Squat

Data Reduction

Statistical Analysis

CHAPTER IV: RESULTS

Demographics

Hip Rotation PROM

Squat Kinematics

$\begin{array}{ll}\text { CHAPTER V: DISCUSSION } & 25\end{array}$

$\begin{array}{ll}\text { Limitations } & 28\end{array}$

Continued Research 
Practical Applications

REFERENCES 


\section{TABLES}

Table

Page

1. Descriptive Data

2. Hip Rotation PROM Data

3. Squat Kinematics Data 


\section{FIGURES}

Figure $\quad$ Page

1. PROM Hip IR Measurement 22

2. PROM Hip ER Measurement 22

3. Baseline Squat With Hip ADD Measures 22

4. TRX Squat With Hip ADD Measures 22 


\section{CHAPTER I: INTRODUCTION}

\section{Background}

Injuries are an inherent part of participation in athletics. According to an epidemiology study completed by Hootman et al. ${ }^{1}$ roughly $54 \%$ of sport related injuries reported were lower extremity injuries, a majority of which were to the knee and ankle. A history of lower extremity injury is a predisposing risk factor for heightened risk of future injury. Research has focused on identifying injury risk factors and on modifying these risk factors to reduce injury risk.

Restricted mobility, or range of motion (ROM), as well as asymmetrical movement and loading may contribute to lower extremity injury risk. Restricted ROM influences available motion during dynamic movement and may contribute to asymmetrical movement and loading. Fortunately, ROM is modifiable through a variety of clinical interventions. However, research and clinical practice are still working toward understanding the most effective means of retraining movement to diminish asymmetry.

Previous research has demonstrated a link between restricted joint ROM and lower extremity movement patterns that may contribute to injury, particularly at the knee. Both distal and proximal joint motion can influence knee motion and in turn influence total lower extremity movement. For instance, restricted passive ankle dorsiflexion ROM is associated with greater medial knee displacement (MKD) during an overhead squat ${ }^{2,3}$ MKD is a clinical observation of knee excursion during movement, and is characterized as the combined motions of knee abduction (valgus), hip adduction, and hip or knee rotation. Knee valgus and hip adduction during dynamic movement patterns are known risk factors for primary ${ }^{4}$ and secondary ${ }^{5}$ anterior cruciate ligament (ACL) rupture. Joint motion proximal to the knee can also greatly influence potential knee injury. ${ }^{6-9}$ Restricted passive hip rotation ROM has been correlated with ACL 
ruptures and re-ruptures caused by non-contact trauma in soccer athletes. ${ }^{6-8}$ Ongoing research needs to better explain the relationship between hip rotation ROM and lower extremity movement patterns.

Movement screenings can identify individuals with lower extremity movement profiles that may heighten injury risk. One such movement is excessive hip adduction during dynamic loading, which presents as a decreased pelvic femoral angle. ${ }^{10}$ Previous research has identified a relationship between excessive hip adduction and known injury risk factors in an otherwise healthy population. ${ }^{2,11}$ Additionally, a currently unpublished work by Begalle et al has observed greater hip adduction motion during a double-leg jump landing on the limb with a history of ACL reconstruction compared to the previously uninjured limb. The amount of hip adduction that occurs during dynamic movement can be influenced by the amount of hip rotation ROM available on each limb. ${ }^{11}$ Therefore, it may be important to investigate the inter-play between available hip rotation ROM and hip adduction angle during a movement screening process.

Clinicians utilize full body movement patterns to observe for dysfunctional movement and any movement asymmetries that could contribute to injury. The double-leg squat is a common full body movement pattern that is used clinically ${ }^{12,13}$ and in the research setting ${ }^{2,3,14-19}$ to identify dysfunctional movement. It can be completed quickly and is relatively easy to use a visual check list to identify dysfunction and asymmetry. ${ }^{20}$

During a double-leg squat, hip adduction results as one limb shifts away from the midline and the other limb maintains a more neutral position or is abducted away from the midline. ${ }^{19}$ Therefore, the limb shifted toward would have a greater degree of hip adduction in comparison from the side they shifted away. This movement pattern can be observed as an asymmetrical weight shift (AWS). Motion analysis instrumentation can be utilized to compute hip adduction 
angles, but three-dimensional motion analysis systems are very expensive and require a great deal of training to use. Tablet based (iPad) motion analysis applications are making motion analysis more readily available to clinicians. These tablet based systems are simple to use and much less costly. Krause et $\mathrm{l}^{21}$ compared the use of tablet based motion analysis and threedimensional motion analysis and found it to be comparably accurate at measuring ROM during functional squat tasks.

Once movement dysfunctions, such as an asymmetrical weight shift, have been identified, corrective exercise interventions should be utilized to re-train movement. The most effective means of decreasing an asymmetrical weight shift are currently unknown. Clinicians have visualized improved squat kinematics while using a TRX suspension trainer. Theoretically, if clinicians make the individual aware of the weight shift, the individual can self-correct the movement pattern. The TRX suspension trainer is a workout system that leverages gravity and an individual's body weight, through holding on to handles attached to straps, anchored to a solid surface such as the wall. The TRX was created by a Navy SEAL who wanted to create an exercise system that could be easily transported. TRX states that while using this system, individuals can focus more on mobility and flexibility training, ${ }^{23}$ making it a useful tool in rehabilitation as well. Unfortunately, there is a large absence of research for its use in the rehabilitation setting.

Therefore, the first aim of this study is to compare passive hip internal rotation ROM (IRROM) and hip external rotation ROM (ER-ROM) between limbs (TWD, AWAY) in a sample of healthy participants that demonstrate an asymmetrical weight shift during the double-leg squat. The second aim is to identify differences in the magnitude of hip adduction (ADD) angle 
asymmetry (AWAY - TWD) during two conditions of the double-leg squat (baseline, TRX) in the same sample.

\section{Independent Variables}

- Research Question 1

○ Limb (2 Levels)

- Limb shifted toward (TWD)

- Limb shifted away from (AWAY)

- Research Question 2

○ Condition (2 Levels)

- Baseline

- TRX

\section{Dependent Variables}

- Research Question 1

- Passive Hip Internal Rotation ROM (IR-ROM)

- Passive Hip External Rotation ROM (ER-ROM)

- Research Question 2

- Hip ADD Difference score between limbs (AWAY - TWD)

\section{Research Questions and Hypotheses}

Research Question 1: Is there a difference in passive hip IR-ROM and ER-ROM between limbs in a sample of healthy individuals with an asymmetrical weight shift when performing a double-leg squat?

Research Hypothesis 1a: Passive hip IR-ROM would be greater on the limb shifted TWD in comparison to the limb shifted AWAY from

Research Hypothesis 1b: Passive hip ER-ROM would be greater on the limb shifted AWAY from in comparison to the limb shifted TWD

Research Question 2: What are the effects of TRX suspension training during the double-leg squat on the calculated limb-to-limb Hip ADD angle difference in comparison to the baseline condition? 
Research Hypothesis 2a: The Hip ADD angle difference scores will decrease in the TRX squat condition compared to BASE 


\section{CHAPTER II: REVIEW OF RELATED LITERATURE}

\section{Epidemiology}

Unilateral dominance or daily habits, such as hand or leg dominance can contribute to asymmetries, just as injuries can. Asymmetries during dynamic movements are common in healthy people and those with injury history, but asymmetries are believed to predispose individuals to injury risk. Examples can be found from restrictions in the ankles affecting movement in the knee or hips ${ }^{18}$ or restrictions in the shoulders causing deficits in the hips; ${ }^{24}$ this line of research further emphasizes the need to understand the body's interconnectedness through the kinetic chain. Functional movement patterns can be used to screen for injury risk, making it easy to identify and then potentially modify the asymmetry before injury, or further injury, can occur. ${ }^{12,13,20}$ This study focuses on identifying lower extremity asymmetries by analyzing squat mechanics and identifying.

\section{Relevant Anatomy}

\section{Ankle}

The lower extremity is broken down into the foot, ankle, lower leg, knee and the hip. The talocrural joint, commonly referred to as the ankle joint, consists of the tibia and fibula, called the lower leg or shank, which sit upon the talus. ${ }^{25}$ The talocrural joint is a hinge joint and is responsible for the dorsiflexion and plantar flexion motions at the ankle, with the help from the triceps surae, gastrocnemius, soleus and plantaris muscles, which concentrically plantar flex the ankle and eccentrically dorsiflex it. ${ }^{25}$ Ankle plantar flexion is the motion of stepping on a gas pedal, or pointing one's toes towards the ground. Dorsiflexion is the opposite action, such as lifting off a gas pedal or bringing one's toes towards their face. The normal passive, non weightbearing dorsiflexion is $11-25^{\circ 26,27}$ where normal weight-bearing lunge range of motion is 
considered greater than $40^{\circ} .{ }^{15,28}$ Within the talocrural joint is the distal tibiofibular joint, which allows for proper translations over the talus. The musculature of the lower leg and ankle are separated into four compartments: anterior, lateral, deep posterior and superficial posterior compartments. ${ }^{25}$ In the lateral compartment, the peroneus longus and brevis help evert and plantarflex the ankle. ${ }^{25,28,29}$ These two muscles also help act as a dynamic restraint to help prevent lateral ankle sprains. ${ }^{25,28,29}$ The superficial posterior compartment holds the gastrocnemius, the plantaris and the soleus, also called the triceps surae. ${ }^{25}$ The triceps surae is responsible for plantar flexion, as well as the gastrocnemius and plantaris assist in knee flexion, as they cross two joints. ${ }^{25}$ These are the group of muscles that, when tight, can be responsible for restrictions in ankle dorsiflexion. ${ }^{25}$ When dorsiflexion is happening with the knee straight, the gastrocnemius is stretched across both joints, and restrictions are greater yet. ${ }^{30}$

\section{Knee}

Moving up the kinetic chain, the knee is comprised of the patellofemoral joint and the tibiofemoral joint. ${ }^{25}$ The patellofemoral joint is the patella, a sesamoid bone that sits within the patellar tendon and articulates the femur in the patellar groove. ${ }^{25}$ The tibiofemoral joint is made of the femur and the tibia, the joint most commonly referred to as the knee. ${ }^{25}$ The movements that happen at the tibiofemoral joint include flexion and extension, internal and external rotation, and abduction and adduction. ${ }^{25}$ During flexion and extension in a weight bearing position, the femur moves on the tibia, where during non-weight bearing position the tibia moves on the femur. ${ }^{25}$ Another movement pattern unique to the knee is the screw-home mechanism. Due to the larger medial femoral condyle, during the last $15-30^{\circ}$ of knee extension, the tibia externally rotates about $20^{\circ}$ to obtain the full extension. ${ }^{31-33}$ The large muscles acting upon the knee are the quadriceps, the hamstrings, the gastrocnemius. ${ }^{25}$ The quadriceps muscles include the rectus 
femoris, which acts on both the hip and the knee; and the vastus medialis, vastus lateralis, and vastus intermedius that only act upon the knee. ${ }^{25}$ As a group they control knee extension, and the vastus medialis also controls medial glides of the patella. ${ }^{25}$ The hamstring muscles are made up of the semimembranosus and semitendinosis, which run down the medial side of the posterior thigh, and the biceps femoris, which runs down the lateral side of the posterior thigh. ${ }^{25}$ This group as a whole also cross two joints, thus acting as knee flexors as well as hip extensors. ${ }^{25}$ They also aid in rotations of the tibia, internal rotation for the semimembranosus and semitendinosus and external rotation for the biceps femoris; being large muscle groups that run down the thigh and along the outside of the tibiofemoral joint, they also aid as dynamic restraints to prevent valgus and varus forces. ${ }^{25}$

\section{Lumbo-Pelvic-Hip Complex}

The lumbo-pelvic-hip complex is a group of five joints made up of the femur, acetabulum, the illium, ischium, and pubis known as the innominate bones; coccyx, sacrum, and lumbar vertebrae. ${ }^{25}$ The true hip joint, or coxofemoral joint, is a ball-and-socket joint made of the femur and the acetabulum. ${ }^{25}$ This is one of the most stable joints in the body, due to the deep acetabulum, size and strength of the ligaments and muscles, and a strong joint capsule. ${ }^{25}$ Movement in all three planes occurs at the coxofemoral joint: flexion and extension, abduction and adduction, and internal and external rotations. ${ }^{25}$ On the posterior side there is the sacroiliac joints, made of the sacrum and both ilia. ${ }^{25}$ Superior to the sacroiliac joint is the lumbosacral joint and then each joint formed by the vertebrae to make the bony foundation for the trunk. ${ }^{25}$ This allows for flexion and extension, rotations, and lateral flexion to either side. ${ }^{25}$ The muscles that make up the anterior hip muscles are the rectus femoris, the sartorius, and the iliopsoas muscles (illiacus, psoas major, psoas minor). ${ }^{25}$ All five of these muscles aid in flexing the hip, as well as 
the sartorius helps externally rotate and abduct the hip. ${ }^{25}$ Laterally, the gluteus medius and tensor fasciae latae abduct and the gluteus medial externally rotates where the tensor fasciae latea internally rotates. ${ }^{25}$ The posterior hip musculature included the hamstrings and the gluteus maximus, which is also a hip extensor. ${ }^{25}$

Muscles, and muscle imbalances, can also play a part in asymmetries with movements. The over activity of one muscle, and thus the decreased performance of another can cause greater pull to be in one direction. One reason they may demonstrate asymmetrical hip shift during squat potentially would be an imbalance of internal/external hip rotations available. Due to the extensive and large amount of support surrounding the hip, it is a stable joint. It often loses mobility, to allow for more stability and the ability to keep people standing upright and completing loading and dynamic movements.

\section{Importance of Internal and External Hip Rotation}

Hip range of motion is important for the function of many multidirectional movements in daily activities as well as sports performance. Deficient motion can alter movement throughout the kinetic chain and potentially predispose individuals to increased injury risk. Hip internal and external range of motion deficits are believed to play a role in increased risk of ACL injuries in both males and females. ${ }^{6,9,34}$ Lopes et $\mathrm{al}^{6}$ compared passive hip internal rotation, external rotation, total rotation arc (internal + external rotations) and abduction angles in participants who experienced contact and non-contact ACL ruptures and found that individuals who experienced non-contact ruptures had statistically significant restrictions in all ranges of motion compared to those who experienced a contact ACL tear. Tainaka et al $^{34}$ also researched active hip range of motion measures in participants with and without a history of ACL injury. They also found that participants with a history of ACL injury had less hip internal and external range of motion 
measures compared to those in the control group. Both studies were retrospective in nature, meaning range of motion measurements were taken after they had already sustained an injury, therefore it is unknown if the differences were present prior to injury.

\section{The Effect of Lower Extremity Injury on Asymmetrical Movement}

\section{Anterior Cruciate Ligament (ACL) Sprains}

ACL tears can occur via a contact or non-contact injury mechanism resulting from a pivot of the knee. Women are more susceptible to suffering from non-contact ACL tears during sport, specifically basketball and soccer, compared to men. ${ }^{35}$ Non-contact ACL injuries are due to an individual's own movement patterns as opposed to an object making direct contact with the knee. There are a number of intrinsic and extrinsic risk factors that may contribute to non-contact ACL injuries. Modifiable intrinsic risk factors, such as neuromuscular control and biomechanics are often the focus of interventions. Modifying these risk factors may potentially decreasing the rates of non-contact ACL injuries. ACL injury prevention programs attempt to improve areas such as hip strength, ${ }^{36,37}$ quadriceps and hamstring muscle activation patterns(ratio), ${ }^{37}$ and improving landing and cutting mechanics. ${ }^{36,37}$ ACL injury prevention programs try to address making changes to these areas. ${ }^{38}$ In a meta-analysis completed by Hewett et al, ${ }^{38}$ six studies were collected, analyzed, and found to show significant favor to the implementation of programs that emphasize neuromuscular training programs.

\section{Effects of Injury on Lower Extremity Biomechanics}

Restrictions in ankle dorsiflexion are associated with a greater risk of ankle sprains ${ }^{29,39}$ and also problems further up the kinetic chain, including greater medial knee displacement, ${ }^{40,41}$ greater knee flexion during landing tasks, ${ }^{15,40}$ and greater strain on the patellar tendon. ${ }^{42}$ Begalle et $\mathrm{al}^{40}$ found that during jump landing tasks, participants with smaller ankle dorsiflexion values 
at initial ground contact had larger knee flexion and varus angles as well as hip flexion and internal rotation. Dill et $\mathrm{al}^{15}$ also observed knee and ankle range of motions during jump landing tasks, as well as overhead squat, single-leg squats, in participants with normal and restricted weight bearing lunge tasks; they found that the restricted weight bearing lunge test groups had increased knee flexion angles during overhead and single-leg squats compared to the normal weight bearing lunge test groups. They did not, however, find any statistically significant differences during the jump landing tasks. ${ }^{15}$ Sigward et $\mathrm{al}^{41}$ observed ankle, knee and hip range of motions during drop landing tasks and found a negative correlation associated with hip external rotation and ankle dorsiflexion range of motions compared to frontal knee valgus. Decreased ankle dorsiflexion was determined to account for $10.8 \%$ of the variance of knee varus during the drop landing task, second to the $16.3 \%$ of decreased hip external rotation. ${ }^{41}$ Brown et $\mathrm{al}^{43}$ completed a study performing stop jump tasks and determined that participants with mechanical ankle instability displayed greater hip flexion, greater maximum hip flexion and hip external rotation than those who were labeled as copers. In addition to range of motion changes, Friel et $\mathrm{al}{ }^{44}$ found ipsilateral hip abductor weakness in participants who had at least two ankle sprains on that same side.

Additionally, anterior cruciate ligament damage can also be correlated with specific factors biomechanically that may predispose the athletes to this injury. Anterior cruciate ligament damage is often linked to weakness in hip musculature, increases in hip adduction or internal rotation, ${ }^{3,36,45}$ and medial knee displacement. ${ }^{46}$ Bell et al ${ }^{3}$ identified that their participants with medial knee displacement displayed decreases in ankle plantarflexion strength and increases in passive external rotation as well trended towards having decreased passive, knee-flexed ankle dorsiflexion. Bell et al ${ }^{3}$ noted during the discussion that further research should be completed to 
identify if lower extremity muscle imbalances are present during the overhead squat to help determine if it is a contributing factor to medial knee displacement. Bell et al ${ }^{30}$ later conducted such a study, where isokinetic strength and additional EMG data was collected while completing an overhead squat. They found that participants displaying medial knee displacement had less straight- knee ankle dorsiflexion than the control group. Bell et al ${ }^{30}$ unfortunately did not find statistically significant differences in hip muscle activation between groups while completing the overhead squat, though they noted hip adductor activation during the overhead squats was slightly increased compared to the control group. They concluded by stating it potentially was a neuromuscular control difference between groups, and not a strength deficit. Padua et al ${ }^{18}$ also conducted a similar study, but found that participants with medial knee displacement displayed $34 \%$ greater adductor magnus activation while completing an overhead squat as compared to a control group. All movement patterns are reliant upon multiple movements through the entire kinetic chain, and changes in one area can cause deficits in other areas believed to be unrelated. For the purpose of this study, we are focusing on participants that display an asymmetrical weight shift while completing an overhead squat.

\section{Asymmetrical Weight Shift}

\section{Operational Definition}

An asymmetrical weight shift, also called a lateral hip shift, can be visually identified during a squat as the participant shifting more weight toward one side. ${ }^{10,19}$ The hip adduction angle is comprised of the midpoint of the patella and each anterior superior iliac spine, with the ASIS on the side being measured as the center of the angle. This measurement is often taken this way on the table supine, but can easily be applied to a weight bearing position. ${ }^{26}$ 


\section{Overactive Muscles vs Underactive Muscles}

Muscles that may contribute to an asymmetrical hip shift include the gluteus medius and the adductor group ${ }^{19,20}$ It is hypothesized that during an asymmetrical weight shift, participants have overactive adductors on the side they shift toward and underactive gluteus medius on the side they shift toward. ${ }^{20}$ Looking at the limb shifted away from, it is believed that the roles reverse and the adductors are underactive where the gluteus medius is overactive. ${ }^{20}$ Peterson et $\mathrm{al}^{19}$ conducted a study to identify overactivity and underactivity of the adductors, gluteus maximus, gluteus medius, and hip adductors during an overhead squat in participant with and without a lateral hip shift. They also collected passive range of motion assessment for hip internal and external rotation, hip abduction, knee extension and also a weight-bearing lunge test. ${ }^{19}$ Gluteus medius activation between groups was the only statistically significant muscle activation data Peterson et $\mathrm{al}^{19}$ had collected, finding that the hip shift group had significantly decreased gluteus medias activation. They also found that within the hip shift group, hip internal rotation and total hip range of motion arcs were different between limbs; hip internal rotation was greater on the limb shifted towards, but the limb shifted towards also had a smaller total hip range of motion arc comparted to the limb shifted away from. ${ }^{19}$ Ankle dorsiflexion was also smaller on the limb shifted towards compared to the limb shifted away from within the hip shift group.

\section{Double-Leg Squats Kinematics}

The overhead double leg squat is a full body movement often used on its own or as a part of biomechanical movement screens to identify restrictions or deficits. ${ }^{12,13,20,47}$ Each major segment of the body has a unique role in performing the proper overhead squat, and just like other movements, compensations happen when there are restrictions in other areas. The proper 
squat specifically looks at the following areas, which can be broken down further if needed: feet and ankles, knees, lumbo-pelvic-hip complex and the shoulders or upper extremity. ${ }^{20}$ When looking at the sagittal (side) view of the double-leg squat, the feet should appear to be facing straight forward and the ankles should be dorsiflexing, with the assistance of the triceps surae facilitating that movement. ${ }^{20,48}$ Restrictions in ankle dorsiflexion can cause the center of pressure in the foot to translate from the mid-foot to the toes and the heel to come off the ground, in attempt to gain motion. ${ }^{48}$ The knees should be flexed and not travel anteriorly past the toes. In a study completed by Macrum et $\mathrm{al}^{17}$ a wedge was placed under the toes to grant the participants more ankle dorsiflexion and found a decrease in knee flexion and an increase in medial knee displacement when looking at the frontal plane as well. Oppositely, Bell et al ${ }^{3}$ conducted a study that placed a wedge under the heels of participants who displayed a medial knee displacement during regular double leg squats and found that placing the wedge under the heels helped to correct their medial knee displacement. In a different study completed by Dill et al ${ }^{15}$ a correlation was found between greater ankle dorsiflexion during the weight bearing lunge test and greater knee flexion and ankle dorsiflexion during double leg squat, when compared to those with restricted ankle dorsiflexion. Moving up the kinetic chain, equal weight distribution should be supported on each leg, and hips should be perpendicular to where the participant is facing. The torso should be upright and the arms overhead. While completing a squat, the participant squats down, as if sitting in a chair, completing hip, knee and ankle dorsiflexion while maintaining an upright torso, parallel to the shank, and arms overhead. Any deviation from this pattern is considered a compensation. ${ }^{20}$ Multiple squats should be performed for analysis to ensure that the patterns are consistently found. ${ }^{20}$ 


\section{Suspension Training}

\section{Background}

The TRX suspension training system was developed by a Navy SEAL who wanted to create a system that would allow him to complete his workouts anywhere. ${ }^{23}$ Ten years later it is one of the top portable equipment systems available. Ranging from $\$ 40.00^{49}-\$ 150.00,{ }^{23}$ the portable nature and low cost of the suspension systems are factors that make this tool useful in any athletic setting. The popularity of these systems has grown among military, runners, and professional athletes, but is simple enough to be used by beginners and experts. ${ }^{23}$ The TRX website $^{23}$ advertises that it is perfect for use to improve mobility and flexibility because it "allows you to unload and leverage your bodyweight so you can safely and effectively get more out of your flexibility and mobility training." The statements about the TRX suspension trainer would make this product perfect for use in the rehabilitation setting along with the fitness setting, but unfortunately there is a lack of research on its use in that setting.

\section{Lack of Research for Rehabilitation}

Current research on the TRX or other suspension training systems is limited to the sports performance topics or elderly populations ${ }^{50}$ and out of research pertaining to rehabilitation for athletes. Mok et $\mathrm{al}^{51}$ and Byrne et $\mathrm{al}^{52}$ both utilized the TRX suspension system to be used while completing core exercises, such as planks. Byrne et al ${ }^{52}$ determined that through the use of the suspension training system, their participants had increased abdominal muscle activation while using the TRX system compared to a plank where both hands and feet were on the ground. Mok et $\mathrm{al}^{51}$ analyzed core activation while completing four exercises, plank with hip abduction, hamstring curl, chest press and the $45^{\circ}$ row. They determined that the greatest core activation was recorded while the participants completed the plank with hip abduction and the smallest 
activation while completing the $45^{\circ}$ row. ${ }^{51}$ Both support the use of the suspension training systems for the use of core activation and other muscle strengthening. Gaedtke et $\mathrm{al}^{50}$ used the TRX system for rehabilitation for an older adult population to increase physical activity levels while being able to provide some support through the movements. They recruited eleven older adults for the twelve-week intervention program. At the end of the twelve weeks, all eleven participants reported positive experiences with the TRX system and self-reported improvements in strength, balance and gait. ${ }^{50}$ It is unknown if the claims of the ability of the TRX to "unload and leverage your bodyweight so you can safely and effectively get more out of your flexibility and mobility training" are true. Potentially, the use of a TRX suspension trainer could allow an individual with an asymmetrical weight shift to decrease their asymmetrical loading.

These would be useful and similar parameters to use to apply the TRX system to rehabilitation techniques, but is a missing component from the literature.

\section{Conclusion}

The literature identifies that overhead squats, and squat mechanics are common tasks when analyzing full body movement patterns..$^{2,3,10,12,15-19,48}$ The literature also identifies potential compensations in movement patterns that are believed to predispose individuals to risks of injury. ${ }^{3,6,10,15-19,30,37,40,42-44}$ Suspension training systems advertise that they are useful in improving mobility and flexibility, but are lacking in research pertaining to rehabilitation benefits or uses. ${ }^{23}$ Therefore, the purpose of this study was two-fold. First, the purpose was to determine if there is a difference in passive measures of hip internal and external rotation range of motion between the limb shifted towards and the limb shifted away from during an overhead squat. Secondly, the purpose was to determine the effect of the TRX suspension trainer would on the hip ADD angle difference scores (TWD-AWAY) compared to the baseline condition. 


\section{CHAPTER III: METHODS}

\section{Design}

This project was a controlled laboratory study to compare hip range of motion and hip kinematics with and without a TRX suspension trainer in individuals with an asymmetric weight shift during an overhead squat. The independent variables were (1) Condition: baseline and TRX, and (2) Limb: limb shifted towards, limb shifted away. The dependent variables included (1) passive hip internal rotation range of motion, (2) passive hip external rotation range of motion, and (3) hip adduction angle during the overhead squat.

\section{Participants}

Participants were recruited from Division I and Division III universities in central Illinois via recruitment fliers and speaking in classes. Any recreationally active, college-age student (1830 years old) attending either institution were considered for this study. Recreationally active was defined as exercising 3 times per week for 30 minutes or a total of 90 minutes per week. ${ }^{53,54}$ Thirtysix healthy, college-age participants were initially screened for potential participation and 28 were originally included in the study. Unfortunately, during data reduction, 2 participants had too large or a forward trunk lean and were excluded because measurements could not be obtained, and 2 were excluded because after review, they presented with inconsistencies in the direction they shifted, leaving us with 24 participants (Age: 19.96 (1.46), Height: $175.07 \mathrm{~cm}$ (8.15), Body Mass: $73.18 \mathrm{~kg}(10.44))$ met the criteria to be included in the study. Participants were excluded if any of the following were true: 1) a lower extremity or low back injury in the past 6 months that has kept the individual out of their normal athletic activity for more than 2 days, 2) any surgical operations on their lower extremity or low back, 3) any neurological disorders, 4) experienced pain during or 
had an inability to complete overhead squat, or 5) lack of an asymmetrical weight shift during at least 3 of the 5 baseline squats.

\section{Instrumentation}

Range of motion measurements for passive hip internal and external rotation were collected with a digital inclinometer (SPI-Tronic, Garden Grove, CA). Hip adduction angles during the overhead squat were collected with one iPad Air 2 (Apple, Inc. Cupertino, California, operating system Apple iOS 9.3.1) device on a tripod, positioned $1.0 \mathrm{~m}$ high and $1.5 \mathrm{~m}$ away from participant in the front. The application used to record and analyze the range of motion was Coach's Eye ${ }^{21}$ (TechSmith Corporation, version 5.3.3), a 2D motion analysis app. The TRX Suspension Trainer $^{23}$ (Fitness Anywhere, LLC, San Francisco, CA) is a patented suspension training system that uses nylon straps, handles, loops and a carabiner was also used for the TRX squat.

\section{Procedures}

Prior to participation, all participants read and signed an IRB-approved informed consent document. The participants were asked to wear their own dark colored spandex shorts; women wore a dark colored sports bra and men did not wear a shirt for testing. This clothing was necessary to allow visualization of reflective markers on bony landmarks to calculate hip kinematics. Participants were prepped for the BASE squat by placing reflective markers (stickers) bilaterally on the anterior superior iliac spine (ASIS), midline of the femur, and center of the patella. Participants were also barefoot to ensure all squat movements were natural. All participants completed a demographic survey which helped to confirm inclusion and exclusion criteria. Anthropometric data was collected, including height $(\mathrm{cm})$, body mass $(\mathrm{kg})$, and age (years). 


\section{Participant Screening and Baseline Squat}

All potential participants were screened for an asymmetrical weight shift (lateral) during the performance of five consecutive overhead squats. An asymmetrical weight shift was defined as the mid-sagittal line shifting laterally towards one leg during at least three out of five squats. Participants were instructed to complete the overhead squat with feet shoulder width apart, heels on floor, feet facing forward, and both arms at $90^{\circ}$ shoulder flexion. ${ }^{15}$ From this position, the participants were instructed to bend their knees and lower their hips as if sitting in a chair. ${ }^{15,28}$ Participants were directed to complete a squat motion as deep as comfortable, at least to $60^{\circ}$, and then return back to start position. The speed of each squat was standardized to a two beat descent and two beat ascent with a one beat pause between sets guided by a metronome app set at 60 beats per minute (BPM) (Pro Metronome,EUMLab-Xanin Technology, Berlin, Germany, version 0.12.29). Three practice squats were allowed to become acquainted with the metronome timing and then five consecutive squats were completed and recorded using the 2D motion analysis app, Coach's Eye. The participants that did not display an asymmetrical weight shift during at least three of the five squats, or displayed inconsistencies with the side shifted towards were thanked for their participation and excluded from the study. Any participant that demonstrated an asymmetrical weight shift was asked to continue participation in the study. The investigator manually recorded which leg they shifted toward and which leg they shifted away from during the screening process. The limb shifted towards is the hip that had a smaller hip adduction angle, and the limb shifted away had the larger hip adduction angle. Range of motion assessments were performed immediately following group allocation for participants that qualified for the study. 


\section{Passive Range of Motion (PROM)}

Bilateral PROM measurements were performed and recorded for hip internal rotation (IR-PROM) and hip external rotation (ER-PROM). Both measurements were performed using a digital inclinometer. All PROM measurements were described as the neutral joint position to the point of first resistance. The point of first resistance was defined as the point where the examiner felt resistance from tension in the muscle or the subject expressed discomfort. Intrarater reliability was established prior to data collection (Hip IR-ROM ICC $(3, \mathrm{k})=0.98, \mathrm{SEM}=5.22^{\circ}$; Hip ER-ROM ICC $(3, \mathrm{k})=0.96, \mathrm{SEM}=4.78^{\circ} ;$ Hip ADD Angle $\operatorname{ICC}_{(3, \mathrm{k})}=0.97, \mathrm{SEM}=6.05^{\circ}$.

Participants laid prone on a treatment table with the test knee flexed to $90^{\circ}$ and the other leg resting on the table for both measurements. ${ }^{55}$ The digital inclinometer was lined up with the midline of the anterior tibial shaft placing the end of the inclinometer just distal to the tibial tuberosity ${ }^{55}$ For internal rotation measure, the clinician passively moved the lower leg away from the midline to the endpoint, while still maintaining neutral pelvic alignment. ${ }^{55}$ For the external rotation measure, the lower leg was moved towards the midline to the endpoint, while still maintaining neutral pelvic alignment. ${ }^{55}$ The internal and external measures was repeated for the second hip. The order of limb tested was counterbalanced between participants. Three trials of each motion was recorded and the average of the three trials used for analysis.

\section{TRX Squat}

The TRX squat condition was performed in a similar manner. Participants were instructed based on the recommendations provided through the TRX manual. The instructions were to stand facing the anchor point of the TRX while holding the handles, fully extend both arms, lean back to take out slack and lower hips into a squat position. While in a squat position they were then instructed to pull yourself into a balanced position with lengthened torso, drive through heels and 
extend hips to standing. Participants must have squatted deeper than $60^{\circ}$ but no deeper than $90^{\circ}$ as to not lose the reflective markers as well as to mirror most depths capable without the TRX. Participants were given three practice squats and then five consecutive squats completed at the same cadence as the BASE squat were recorded using the iPad and Coach's Eye applications.

\section{Data Reduction}

All PROM measurements were calculated by taking the average of the three trials. Hip adduction angles were determined using Coach's Eye by drawing a horizontal line between the right and left ASIS and two additional lines from the ASIS markers through the midline of the femur. This angle was recorded using the Angle Tool in Coach's Eye and the reflective markers as reference marks. ${ }^{21}$ Squat kinematics were analyzed at the deepest point of the squat by identifying the lowest vertical point of the reflective marker placed on the participants' manubrium. Hip adduction angle difference scores were calculated between limbs (side shifted TWD, side shifted AWAY from) by subtracting the value on the TWD limb from the value on the AWAY limb (AWAY - TWD). A larger magnitude number indicated a greater difference in the amount of hip adduction observed between limbs. A decrease in this number during the TRX squat condition would indicate a decrease in hip ADD angle difference, or a shift back toward neutral.

\section{Statistical Analysis}

A paired samples t-test was performed to identify within subjects differences between limbs (shifted toward, shifted away) on measures of Hip IR-PROM and Hip ER-PROM.

A second paired samples t-test was performed to compare the hip kinematic difference scores calculated for Hip ADD (AWAY-TWD) between the BASE condition and the TRX condition. 
All statistical analyses were performed using SPSS (IBM SPSS Statistics for Windows, version 21.0; IBM Corp, Armonk, NY). A priori alpha levels were set at $p \leq 0.05$.

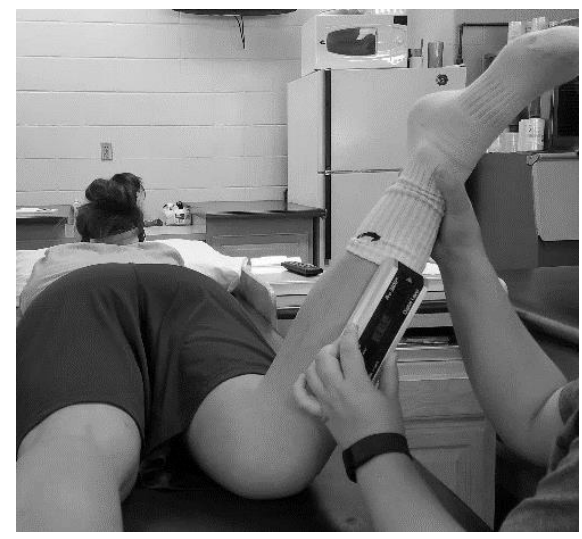

Figure 1: PROM Hip IR measurement

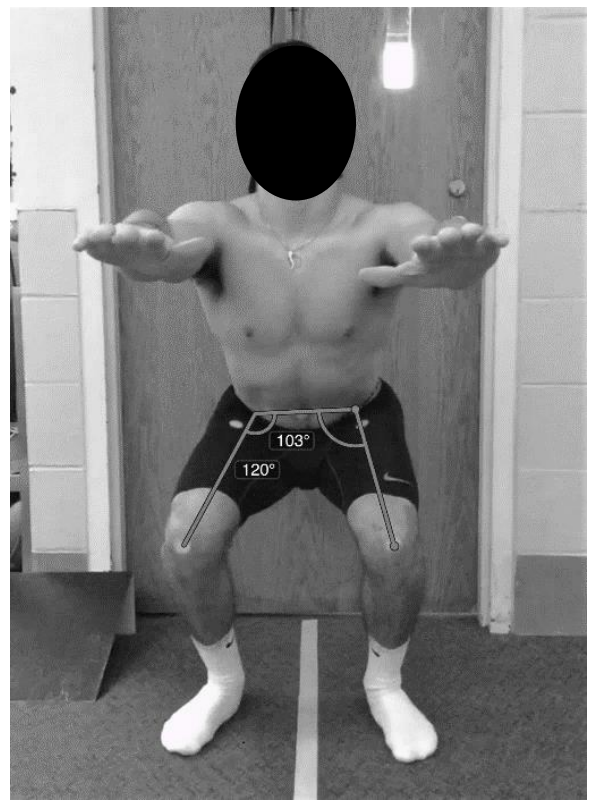

Figure 3: Baseline squat with Hip ADD measures

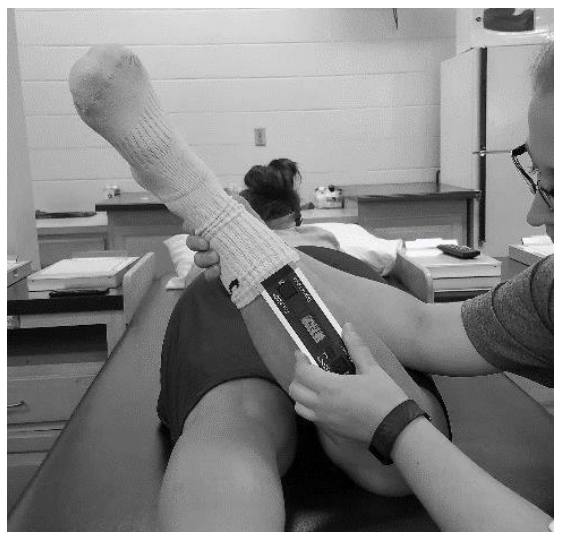

Figure 2: PROM Hip ER measurement

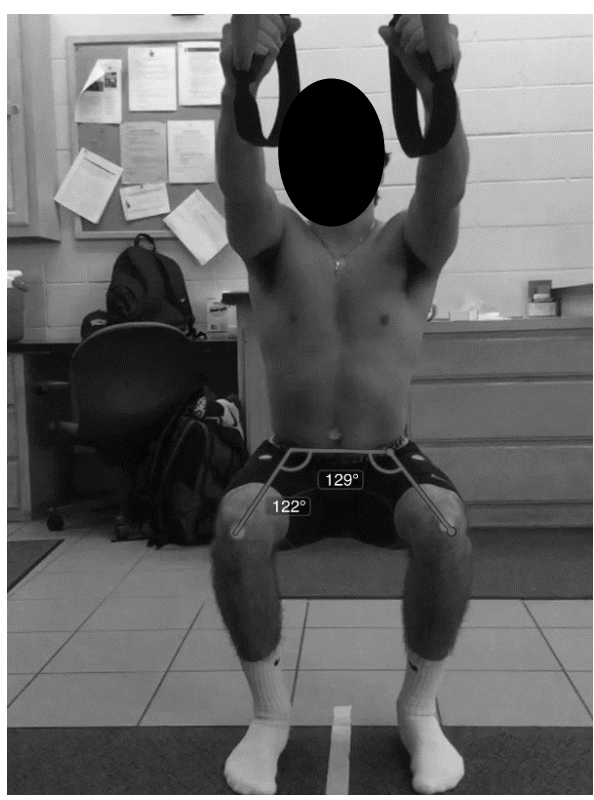

Figure 4: TRX squat with Hip ADD measures 


\section{CHAPTER IV: RESULTS \\ Demographics}

Descriptive data for dominant kicking limb, dominant balance limb, and side shifted toward are reported in Table 1.

\section{Hip Rotation PROM}

No significant differences were observed between limbs on measures of Hip IR-PROM $\left(\mathrm{t}_{(1,23)}=0.271, \mathrm{p}=0.79\right)$ or Hip ER-PROM $\left(\mathrm{t}_{(1,23)}=0.814, \mathrm{p}=0.42\right)$.

\section{Squat Kinematics}

Calculated difference scores for hip adduction during the squat conditions (away-toward) were significantly different between the BASE and TRX conditions $\left(\mathrm{t}_{1,23)}=3.11, \mathrm{p}=0.005\right.$, effect size $=0.63$ ). Values are reported in Table 2 . The mean value decreased during the TRX condition, indicating a lessening of the asymmetrical weight shift.

Table 1. Descriptive Data

\begin{tabular}{|l|c|c|}
\hline & Right & Left \\
\hline Dominant Balance Limb & 19 & 5 \\
\hline Dominant Kicking Limb & 23 & 1 \\
\hline Side Shifted Towards & 12 & 12 \\
\hline
\end{tabular}


Table 2. Hip Rotation PROM Data

\begin{tabular}{|l|c|c|c|}
\hline & TWD & AWAY & p-value \\
\hline Hip IR-ROM & $39.30(11.23)$ & $40.39(17.58)$ & $\mathrm{P}=0.79$ \\
\hline Hip ER-ROM & $33.69(9.28)$ & $35.24(22.73)$ & $\mathrm{P}=0.42$ \\
\hline
\end{tabular}

Table 3. Squat Kinematics Data

\begin{tabular}{|l|c|c|c|}
\hline & Away Mean (SD) & TWD (SD) & Difference Scores (SD) \\
\hline Baseline Squat & $123.74(10.71)$ & $111.82(10.23)$ & $11.93(7.55)$ \\
\hline TRX Squat & $130.38(11.92)$ & $123.99(11.32)$ & $6.39(9.78)$ \\
\hline
\end{tabular}




\section{CHAPTER V: DISCUSSION}

Our most important finding was that the TRX suspension trainer influenced a decrease in asymmetrical weight shift in our participants, indicated by a decrease in the hip adduction angle limb-to-limb difference. This result did support our hypothesis. There is limited research investigating techniques to improve asymmetrical weight shifts during a squat task and this is the first study to investigate the potential use of suspension training to decrease asymmetrical movement.

In this sample of healthy participants, no statistically significant limb to limb differences were observed when comparing passive hip IR and ER in the limb shifted TWD versus the limb shifted away from. This finding did not support our hypothesis and conflicts with previous research. ${ }^{9,19}$ Previous research has shown that restrictions in hip IR ROM are associated with heightened risk of anterior cruciate ligament (ACL) injury in the knee. ${ }^{9,56}$ Research has also demonstrated that asymmetry in the amount of IR and ER on one side, termed asymmetry of unilateral hip rotation (AUHR), is associated with hip adduction excursion $(\mathrm{R}=0.36)$ during a single-leg landing task. ${ }^{57}$ Based on previous research highlighting the importance of hip rotation motion, we speculated we would see side-to-side differences in a sample of healthy participants demonstrating an asymmetrical weight shift during the double-leg squat. We did calculate the same AUHR value as the previous authors and found the limb shifted TWD (12.13 \pm 13.43$)$ was greater than the limb shifted away from (2.65 \pm 19.80$)$, but statistical significance was not found $(\mathrm{p}=0.058)$ likely due to the large standard deviations. The average values for hip IR and ER in our sample did fall within normative values for both hip IR $\left(35-45^{\circ}\right)$ and ER $\left(45^{\circ}\right)$ potentially limiting our ability to identify differences. ${ }^{58,59}$ Future investigations should recruit participants with hip rotation restrictions to further tease out the impact on asymmetry in movement. 
One of the greatest needs in the clinical and research setting is to continue to identify altered movement and loading patterns and then better understand what is driving those movement patterns so we can change them. In particular, asymmetrical shifting of one's body weight to one side more than the other during a double-leg activity may be problematic because the distribution of loading is not equal. These asymmetries may be further exaggerated when functional movement speeds are increased, when transition from a double-leg to a single-leg task or the height from which we land is increased. ${ }^{60,61}$ Asymmetrical weight shifts have been identified in populations with a history of lower extremity injury. ${ }^{11,61-63}$ If these asymmetries are not corrected, they may result in further injuries. ${ }^{63}$ However, our research recruited healthy, physically active, participants that also demonstrated an asymmetrical weight shift. Often in research we operationally define a limb to be dominant by self-selecting it as the limb they would prefer to kick a soccer ball for maximum distance, or a dominant balance limb may be defined as the limb they would choose to land on if they could only pick one. It seems likely that healthy individuals may tend to shift more toward their non-dominant (balance) limb during a double-leg squat when an asymmetry exists. In the current study, $79 \%$ (19 out of 24) stated that their dominant balance limb was their right limb, but there were an equal number of individuals that shifted toward their right $(n=12)$ and left $(n=12)$ limbs. This descriptive finding highlights that there was not a tendency to shift more toward the dominant or non-dominant side in this healthy sample. Future research could include a more detailed injury history to determine if there is a correlation between limbs shifted toward/away from and individuals' injury history.

The difference in hip adduction angles between limbs during the baseline condition $\left(11.93^{\circ} \pm 7.55\right)$ was a larger magnitude difference compared to when the same participants performed the double-leg squat with the TRX suspension trainer $\left(6.39^{\circ} \pm 9.78\right)$. Based on the 
calculation method for this difference (Away - TWD), a decrease in the magnitude of this number indicates a shift in weight-bearing back toward the limb they were once shifting away from. Therefore, the TRX condition showed a statistically significant $(\mathrm{p}=0.005)$, as well as a clinically significant $(\mathrm{d}=0.63)$, decrease in the magnitude of the difference indicating they moved back to a more neutral position. This is the first study to investigate the use of a TRX suspension trainer in the rehabilitation setting to improve an asymmetrical weight shift during the double-leg squat.

During the TRX condition, the TWD limb ADD angle increased, showing a shift to a more neutral position. The investigators note that there was also an increase in the limb shifted AWAY, as well as the decrease in the difference scores, showing a more even squat. It is possible that because the TRX allows the individuals to squat to deeper depths than their TRX condition, that allowed to an increase in both limbs ADD angles. This should be investigated further with additional measurement tools to best explain fully the TRX's effect on the asymmetrical weight shift.

The stated purpose of the TRX suspension trainer is to allow individuals to unload and leverage their bodyweight so they can safely and effectively get more out of their flexibility and mobility training. ${ }^{23}$ There are a number of reasons that somebody may shift their body weight while performing a double-leg squat, including mobility and neuromuscular control. We hypothesized that suspension training in this sample may allow them to unload their body weight and eliminate potential limitations caused by stability issues and perform a more symmetrical squat. This premise came from the selective functional movement assessment (SFMA), which is a movement based diagnostic system. This system allows clinicians to systematically find the cause of symptoms by breaking down dysfunctional movement patterns. Breakout for the deep 
squat task utilizes an assisted deep squat to identify if a patient has the mobility to move into the deep squat but lacks the neuromuscular control to do so. ${ }^{22}$ In the current study, the TRX suspension trainer may have helped to make the individual aware of their asymmetrical weight shift due to the unequal tension (or pull) they would feel on the handles, thereby guiding the participants to begin correcting their movement automatically. ${ }^{22}$ The use of a TRX suspension trainer may be a beneficial rehabilitation tool to enable patients to improve symmetry during double-leg movements.

\section{Limitations}

It was important to the current researchers to utilize a motion analysis tool that was readily available to clinicians. The iPad based motion analysis system (Coach's Eye) was an efficient and cost effective way to record videos, identify asymmetrical weight shifts, identify the deepest part of the squat, and calculate hip adduction angles. However, there were instances where the forward trunk flexion of a participant occluded the ASIS markers and we were unable to use their data. This is a limitation as we had to exclude participants that potentially could have lent greater insight into answering our research question. Also, because it is a 2D measure, it does not measure any transverse plane motion, which may also be a factor in an asymmetrical weight shift. If the investigators could measure the rotational component as well, it may have provided an even more detailed description of the AWS. Previous research has been conducted by Krause et $\mathrm{al}^{21}$ to compare the accuracy for this $2 \mathrm{D}$ motion analysis application, and though they analyzed sagittal ROM instead of the frontal ROM, found that it was a comparable analysis to the Vicon system.

The current study recruited and screened otherwise healthy participants that demonstrated an asymmetrical weight shift during the double-leg squat. Our findings cannot be generalized to 
an injured population. These results provide valuable pilot evidence to incorporate a TRX suspension trainer in an injured or previously injured population in research and clinical practice moving forward.

\section{Continued Research}

Previous research has demonstrated an overactive hip adductor and underactive gluteus medius muscle on the limb shifted toward in comparison to the limb shifted away from. ${ }^{19}$ Similarly, research has demonstrated that an overactive hip adductor and underactive gluteus medius can contribute to medial displacement at the knee. ${ }^{64}$ Future research should include the study of muscle activation, and a force plate or pressure sensing mat under the feet, with and without the TRX suspension trainer to fully describe what is occurring at the neuromuscular level as the individuals shift back toward a more equal distribution of weight.

\section{Practical Applications}

The TRX suspension trainer was an effective tool in decreasing the hip ADD angle differences during a double-leg squat in an acute setting. This helps supports the use for the TRX suspension trainer in the rehabilitation setting for correcting the asymmetrical weight shift. The Coach's Eye application was also a useful and cost effective clinical tool in helping to identify and measure the asymmetrical weight shifts. This tool can easily be used for other movement pattern screens and may be a useful tool in providing visual feedback to patients as well. 


\section{REFERENCES}

1. Hootman JM, Dick R, Agel J. Epidemiology of collegiate injuries for 15 sports: summary and recommendations for injury prevention initiatives. J Athl Train. 2007;42(2):311-319.

2. Bell DR, Vesci BJ, DiStefano LJ, Guskiewicz KM, Hirth CJ, Padua DA. Muscle activity and flexibility in individuals with medial knee displacement during the overhead squat. Athletic Training \& Sports Health Care. 2012;4(3):9.

3. Bell DR, Padua DA, Clark MA. Muscle strength and flexibility characteristics of people displaying excessive medial knee displacement. Arch Phys Med Rehabil. 2008;89(7):1323-1328.

4. Hewett TE, Zazulak BT, Myer GD, Ford KR. A review of electromyographic activation levels, timing differences, and increased anterior cruciate ligament injury incidence in female athletes. Br J Sports Med. 2005;39(6):347-350.

5. Paterno MV, Schmitt LC, Ford KR, et al. Biomechanical measures during landing and postural stability predict second anterior cruciate ligament injury after anterior cruciate ligament reconstruction and return to sport. Am J Sports Med. 2010;38(10):1968-1978.

6. Lopes OV, Gomes JL, de Freitas Spinelli L. Range of motion and radiographic analysis of the hip in patients with contact and non-contact anterior cruciate ligament injury. Knee Surg Sports Traumatol Arthrosc. 2016;24(9):2868-2873.

7. Ellera Gomes JL, Palma HM, Ruthner R. Influence of hip restriction on noncontact ACL rerupture. Knee Surg Sports Traumatol Arthrosc. 2014;22(1):188-191.

8. Gomes JL, de Castro JV, Becker R. Decreased hip range of motion and noncontact injuries of the anterior cruciate ligament. Arthroscopy. 2008;24(9):1034-1037. 
9. VandenBerg C, Crawford EA, Sibilsky Enselman E, Robbins CB, Wojtys EM, Bedi A. Restricted Hip Rotation Is Correlated With an Increased Risk for Anterior Cruciate Ligament Injury. Arthroscopy. 2017;33(2):317-325.

10. Powers CM. The influence of altered lower-extremity kinematics on patellofemoral joint dysfunction: a theoretical perspective. J Orthop Sports Phys Ther. 2003;33(11):639-646.

11. Powers CM. The influence of abnormal hip mechanics on knee injury: a biomechanical perspective. J Orthop Sports Phys Ther. 2010;40(2):42-51.

12. Cook G, Burton L, Hoogenboom B. Pre-participation screening: the use of fundamental movements as an assessment of function - part 1. NAm J Sports Phys Ther. 2006;1(2):62-72.

13. Cook G, Burton L, Hoogenboom B. Pre-participation screening: the use of fundamental movements as an assessment of function - part 2. N Am J Sports Phys Ther. 2006;1(3):132-139.

14. Butler RJ, Plisky PJ, Southers C, Scoma C, Kiesel KB. Biomechanical analysis of the different classifications of the Functional Movement Screen deep squat test. Sports Biomech. 2010;9(4):270-279.

15. Dill KE, Begalle RL, Frank BS, Zinder SM, Padua DA. Altered knee and ankle kinematics during squatting in those with limited weight-bearing-lunge ankledorsiflexion range of motion. $J$ Athl Train. 2014;49(6):723-732.

16. Kim SH, Kwon OY, Park KN, Jeon IC, Weon JH. Lower extremity strength and the range of motion in relation to squat depth. J Hum Kinet. 2015;45:59-69. 
17. Macrum E, Bell DR, Boling M, Lewek M, Padua D. Effect of limiting ankle-dorsiflexion range of motion on lower extremity kinematics and muscle-activation patterns during a squat. J Sport Rehabil. 2012;21(2):144-150.

18. Padua DA, Bell DR, Clark MA. Neuromuscular characteristics of individuals displaying excessive medial knee displacement. J Athl Train. 2012;47(5):525-536.

19. Peterson K, Prentice W, Padua D, Mauntel T. Muscle Activation and Range of Motion Patterns of Individuals who Display a Lateral Hip Shift During an Overhead Squat. Chapel Hill, NC, University of North Carolina at Chapel Hill; 2015.

20. Clark MA, Lucett SC. NASM's Essentials of Corrective Exercise Training. 1 ed. Philadelphia, PA: Lippincott Williams \&amp; Wilkins; 2011.

21. Krause DA, Boyd MS, Hager AN, Smoyer EC, Thompson AT, Hollman JH. Reliability and accuracy of a goniometer mobile device application for video measurement of the functional movement screen deep squat test. Int J Sports Phys Ther. 2015;10(1):37-44.

22. Cook G, Burton L, Kiesel K, Rose G, Bryant M. Movement. Aptos, CA: On Target Publications; 2010.

23. LLC FA. TRX Training website. 2005; https://www.trxtraining.com/. Accessed October $1,2016$.

24. Laudner K, Wong R, Onuki T, Lynall R, Meister K. The relationship between clinically measured hip rotational motion and shoulder biomechanics during the pitching motion. $J$ Sci Med Sport. 2015;18(5):581-584.

25. Starkey C, Brown SD, Ryan J. Examination of Orthopedic and Athletic Injuries. 3 ed. Philadelphia, PA: F.A. Davis Company; 2010. 
26. Norkin CC, White DJ. Measurement of Joint Motion 4th ed. Philadelphia, PA: F.A Davis Company; 2009.

27. Moseley AM, Crosbie J, Adams R. High- and low-ankle flexibility and motor task performance. Gait Posture. 2003;18(2):73-80.

28. Smith M. Effect of talocrural joint mobilizations on restricted ankle dorsiflexion and kinematics of squatting tasks. North Carolina: Department of Exercise \& Sports Science (Athletic Training), University of North Carolina at Chapel Hill; 2013.

29. Hertel J. Functional Anatomy, Pathomechanics, and Pathophysiology of Lateral Ankle Instability. J Athl Train. 2002;37(4):364-375.

30. Bell DR, Vesci BJ, DiStefano LJ, Guskiewicz KM, Hirth CJ, Padua DA. Muscle activity and flexibility in individuals with medial knee displacement during the overhead squat. Athletic Training \&amp; Sports Health Care. 2012;4(3):9.

31. Kim HY, Kim KJ, Yang DS, Jeung SW, Choi HG, Choy WS. Screw-Home Movement of the Tibiofemoral Joint during Normal Gait: Three-Dimensional Analysis. Clin Orthop Surg. 2015;7(3):303-309.

32. Amiri S, Cooke D, Kim IY, Wyss U. Mechanics of the passive knee joint. Part 1: The role of the tibial articular surfaces in guiding the passive motion. Proc Inst Mech Eng $\mathrm{H}$. 2006;220(8):813-822.

33. Freeman MA, Pinskerova V. The movement of the knee studied by magnetic resonance imaging. Clin Orthop Relat Res. 2003(410):35-43.

34. Tainaka K, Takizawa T, Kobayashi H, Umimura M. Limited hip rotation and non-contact anterior cruciate ligament injury: a case-control study. Knee. 2014;21(1):86-90. 
35. Prodromos CC, Han Y, Rogowski J, Joyce B, Shi K. A meta-analysis of the incidence of anterior cruciate ligament tears as a function of gender, sport, and a knee injury-reduction regimen. Arthroscopy. 2007;23(12):1320-1325.e1326.

36. Pollard CD, Sigward SM, Powers CM. Gender differences in hip joint kinematics and kinetics during side-step cutting maneuver. Clin J Sport Med. 2007;17(1):38-42.

37. Hewett TE, Myer GD, Ford KR. Anterior cruciate ligament injuries in female athletes: Part 1, mechanisms and risk factors. Am J Sports Med. 2006;34(2):299-311.

38. Hewett TE, Ford KR, Myer GD. Anterior cruciate ligament injuries in female athletes: Part 2, a meta-analysis of neuromuscular interventions aimed at injury prevention. Am J Sports Med. 2006;34(3):490-498.

39. Hertel J. Sensorimotor deficits with ankle sprains and chronic ankle instability. Clin Sports Med. 2008;27(3):353-370, vii.

40. Begalle RL, Walsh MC, McGrath ML, Boling MC, Blackburn JT, Padua DA. Ankle Dorsiflexion Displacement During Landing is Associated With Initial Contact Kinematics but not Joint Displacement. J Appl Biomech. 2015;31(4):205-210.

41. Sigward SM, Ota S, Powers CM. Predictors of frontal plane knee excursion during a drop land in young female soccer players. J Orthop Sports Phys Ther. 2008;38(11):661-667.

42. Backman LJ, Danielson P. Low range of ankle dorsiflexion predisposes for patellar tendinopathy in junior elite basketball players: a 1-year prospective study. Am J Sports Med. 2011;39(12):2626-2633.

43. Brown CN, Padua DA, Marshall SW, Guskiewicz KM. Hip kinematics during a stopjump task in patients with chronic ankle instability. J Athl Train. 2011;46(5):461-467. 
44. Friel K, McLean N, Myers C, Caceres M. Ipsilateral hip abductor weakness after inversion ankle sprain. J Athl Train. 2006;41(1):74-78.

45. Zeller BL, McCrory JL, Kibler WB, Uhl TL. Differences in kinematics and electromyographic activity between men and women during the single-legged squat. $\mathrm{Am}$ J Sports Med. 2003;31(3):449-456.

46. Mauntel TC, Post EG, Padua DA, Bell DR. Sex Differences During an Overhead Squat Assessment. J Appl Biomech. 2015;31(4):244-249.

47. Choi HS, Shin WS. Validity of the lower extremity functional movement screen in patients with chronic ankle instability. J Phys Ther Sci. 2015;27(6):1923-1927.

48. Schoenfeld BJ. Squatting kinematics and kinetics and their application to exercise performance. J Strength Cond Res. 2010;24(12):3497-3506.

49. LLC WE. WOSS Attack Trainer. 2016; http://www.woss.com/woss-attack-trainer/. Accessed October 1, 2016.

50. Gaedtke A, Morat T. TRX Suspension Training: A New Functional Training Approach for Older Adults - Development, Training Control and Feasibility. Int J Exerc Sci. 2015;8(3):224-233.

51. Mok NW, Yeung EW, Cho JC, Hui SC, Liu KC, Pang CH. Core muscle activity during suspension exercises. J Sci Med Sport. 2015;18(2):189-194.

52. Byrne JM, Bishop NS, Caines AM, Crane KA, Feaver AM, Pearcey GE. Effect of using a suspension training system on muscle activation during the performance of a front plank exercise. J Strength Cond Res. 2014;28(11):3049-3055. 
53. Walsh M, Boling MC, McGrath M, Blackburn JT, Padua DA. Lower extremity muscle activation and knee flexion during a jump-landing task. J Athl Train. 2012;47(4):406413.

54. Wright CJ, Arnold BL, Ross SE, Ketchum J, Ericksen J, Pidcoe P. Clinical examination results in individuals with functional ankle instability and ankle-sprain copers. $J$ Athl Train. 2013;48(5):581-589.

55. Roach S, San Juan JG, Suprak DN, Lyda M. Concurrent validity of digital inclinometer and universal goniometer in assessing passive hip mobility in healthy subjects. Int $J$ Sports Phys Ther. 2013;8(5):680-688.

56. Bedi A, Warren RF, Wojtys EM, et al. Restriction in hip internal rotation is associated with an increased risk of ACL injury. Knee Surg Sports Traumatol Arthrosc. 2016;24(6):2024-2031.

57. Howard JS, Fazio MA, Mattacola CG, Uhl TL, Jacobs CA. Structure, sex, and strength and knee and hip kinematics during landing. J Athl Train. 2011;46(4):376-385.

58. Kendall F, McCreary E, Provance P, Rodgers M, Roman W. Muscles: Testing and Function with Posture and Pain. 5 ed. Baltimore, MD: Lippincott Williams \& Wilkins; 2005.

59. Hoppenfeld S. Physical Examination of the Spine and Extremities. East Norwalk, CT: Appleton-Centrury-Crofts; 1976.

60. Donohue MR, Ellis SM, Heinbaugh EM, Stephenson ML, Zhu Q, Dai B. Differences and correlations in knee and hip mechanics during single-leg landing, single-leg squat, double-leg landing, and double-leg squat tasks. Res Sports Med. 2015;23(4):394-411. 
61. Paterno MV, Ford KR, Myer GD, Heyl R, Hewett TE. Limb asymmetries in landing and jumping 2 years following anterior cruciate ligament reconstruction. Clin J Sport Med. 2007;17(4):258-262.

62. Hewett TE, Myer GD. The mechanistic connection between the trunk, hip, knee, and anterior cruciate ligament injury. Exerc Sport Sci Rev. 2011;39(4):161-166.

63. Webster KE, Feller JA, Leigh WB, Richmond AK. Younger patients are at increased risk for graft rupture and contralateral injury after anterior cruciate ligament reconstruction. Am J Sports Med. 2014;42(3):641-647.

64. Mauntel TC, Begalle RL, Cram TR, et al. The effects of lower extremity muscle activation and passive range of motion on single leg squat performance. J Strength Cond Res. 2013;27(7):1813-1823. 